Nilson and Pettersson have recently repeated their determination of the specific heat of beryllium, and find these numbers:-

$0^{\circ}-50^{\circ}$ spec, heat $=0.3973: 0^{\circ}-100^{\circ}$ spec. heat $=0^{\circ} 4246$, $0^{\circ}-200^{\circ}, \quad=0^{\circ} 475: 0^{\circ}-300^{\circ},, \quad=0^{\circ} 5^{\circ} 55^{\circ}$. If the atomic weight is taken as 13.6 then the atomic heat for the interval-

$0^{\circ}-50^{\circ}=5.46: 0^{\circ}-100^{\circ}=5.79: 0^{\circ}-200^{\circ}=6.48: 0^{\circ}-300^{\circ}=6.9$, hence the Swedish chemists conclude that the atomic weight of beryllium is $13^{\circ} .6$.

But in the last number of the Berichte of the German Chemical Society, Lothar Meyer has calculated, from Nilson and Pettersson's numbers, the true specific heat (i.e. the ratio between the quantity of heat required to raise unit weight of the given substance through $\mathrm{I}^{\circ}$, starting from the given temperature, and the quantity of heat required to raise unit weight of standard substance through $I^{\circ}$, also starting from the given temperature) of beryllium for various temperatures : his results are as follows:-

$(\gamma=$ true specific heat at temperature $t: \Delta \gamma=$ value of increase of specific heat for $\left.I^{\circ}\right)$.

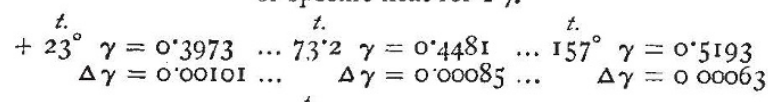

$$
\stackrel{t .}{2 .} \cdot 6^{\circ} \cdot S \gamma=0.5819 \text {. }
$$

Hence the atomic heats of beryllium are :-

$$
\begin{array}{rrrcccc}
t . & & & \text { Be }=9 \cdot 1 . & & & \text { Be }={ }_{13} \cdot 65 . \\
23^{\circ} & \ldots & \ldots & 3.62 & \ldots & \ldots & 5.43 \\
73^{\circ} & \ldots & \ldots & 4.08 & \ldots & \ldots & 6 \cdot 12 \\
157^{\circ} & \ldots & \ldots & 4.73 & \ldots & \ldots & 7.10 \\
257^{\circ} & \ldots & \ldots & 5.29 & \ldots & \ldots & \text { S. } 94
\end{array}
$$

The value of $\Delta \gamma$ decreases as the temperature rises; in this respect beryllium resembles boron, carbon, and silicon. For other elements whose specific heats increase with increase of temperature the value of $\Delta \gamma$ also increases. Lothar Meyer therefore concludes that beryllium is analogous to boron, carbon, and silicon, in that its specific heat increases as temperature increases, and in that the value of this increase is less for $1^{\circ}$ at high than at low temperatures. Hence the atomic weight of beryllium is almost certainly $9^{\circ} \mathrm{x}$, the oxide is $\mathrm{BeO}$, and the metal finds its place in Mendelejeff's system of classification of the elements according to their atomic weights.

\section{THE PHOTOPHONE}

MANY readers of NATURE will doubtless be glad to know that Mr. Graham Bell's extraordinary experiments may be repeated on a small scale with very simple apparatus, no special appliances being required beyond the mirror transmitter and the selenium receiver, both of which may be easily constructed. I propose to give a short description of an arrangement which has in my hands been very successful.

The mirror is made of the thin mica which is sold by opticians for covering carte de visite photographs. It is cut by scissors into a circle $2 \frac{1}{4}$ inches in diameter, and silvered by the process for silvering glass specula. The box in which it is mounted is an ordinary wood turned box $2 \frac{1}{2}$ inches in diameter. A circular hole of about 2 inches diameter is cut in the lid, behind which the mirror is laid with the reflecting side outwards, a flat ring of vulcanised india-rubber of suitable size and thickness being placed behind the mirror; when the box is closed the ring should hold the mirror firmly in position. If the lid screws on, so much the better. At the bottom of the box is cut a hole, into which is glued one end of a flexible speaking-tube 18 inches long, having at its other end a wooden mouthpiece. It will be found convenient to attach a short wooden arm to the box in a direction perpendicular to its axis. By means of this arm the transmitter may be hel in a clamp in any desired position.
This completes the transmitter as described by Mr. Bell. I have made a small addition which, though not essential, is a decided improvement. At the back of the mirror I cemented a disk of calico $\mathrm{I}$ inch in diameter, in the centre of which had been previously inserted a loop of silk half an inch long. A hole $\frac{1}{8}$ inch diameter is bored perpendicularly in the side of the box at a point about $\frac{1}{2}$ inch from the mirror end of it, and in this hole is inserted a piece of watch-spring Is inch long, with its flat sides parallel to the top and bottom of the box. The spring is fixed into the hole with wooden plugs so that one end is flush with the outer surface of the box; the other end where it intersects the axis is bent into a shallow hook. Into this hook is slipped the silken loop, and the tension of the spring draws the mirror into a slightly concave form, and seems to make it respond more perfectly to sound vibrations.

By far the most important part of the whole apparatus is the selenium "cell." After making some dozens of different forms, most of which were more or less sensitive, but none satisfactory, I tried the one now to be described, which turned out very successful. Take a slip of mica $2 \frac{1}{4}$ inches long and $\frac{3}{4}$ inch broad, and beginning at $\frac{1}{4}$ inch from one end, wind round it in the form of a flat screw some No. 40 copper wire. The pitch of the screw is $1 \vec{v}$ inch, that is, each wire on the two faces of the mica is $\frac{1}{1 \frac{1}{6}}$ inch from its neighbours. Continue winding up to $\frac{1}{4}$ inch from the other extremity; then fix the two ends of the wire by passing them through holes drilled in the mica. Now take a second wire and carefully wind this on beside the other, thus forming a second screw, the threads of which are midway between those of the original one. Fix this as before. Great care must be taken that the two wires do not touch each other at any point: it will be well to make sure of this by testing with a galvanometer before proceeding further. If a lathe is at hand, the tedious operation of winding may be very greatly facilitated. Turn a cylinder of hard wood $4 \frac{1}{2}$ inches long and $I$ inch in diameter: cut this cylinder longitudinally into two equal parts, and between the two semi-cylinders thus formed place, sandwich-like, a slip of mica of equal breadth. Secure the ends with screws. Smooth down the whole in the lathe, and when the edges of the mica are quite flush with the surface of the wood, cut upon the cylinder a screw of thirty-two threads to the inch. On removing the mica from the cylinder its two edges will be found to be beautifully and regularly notched. Wind the first wire into alternate notches, and the second into the others. The wire should be annealed to take away its springiness and make it lie flat, and the mica should be stout enough to bear tight winding without buckling.

For the succecding operation a retort-stand at least I 5 inches high is convenient. Fix one ring 15 inches above the foot; on a lower ring stand a medium-sized Bunsen burner. On the top ring lay a flat sheet of brass ${ }_{16}^{1}$ inch thick, and on the brass a piece of mica (to save waste selenium). Place the embryo cell on the mica, laying small weights on its two ends to keep it steady and bring it into closer contact. Having brought the Bunsen burner. close under the brass, melt a few grains of vitreous selenium in a small spoon and let four or five drops fall upon different parts of the cell. Spread the melted selenium evenly over the surface with a slip of mica, pressing it well between the wires. During this process the temperature must be carefully regulated by raising or depressing the burner. If it is not high enough, tae selenium will begin to crystallise; if too high, the selenium will gather up into drops, being apparently repelled from the surface of the cell. The temperature should in fact be just above the fusing point of crystalline selenium. When a smooth surface is obtained, quickly remove the cell with microscope forceps and let it cool. Its surface will now be smooth and lustrous.

The cell must next be annealed. And here my expe- 
rience differs in a remarkable manner from that of $\mathrm{Mr}$. Bell, as stated in his celebrated lecture. It is true that selenium may be rendered crystalline in "a few minutes," but in this condition I find it far less sensitive to light than after it has undergone a process of long heating and slow cooling. My method is as follows:-The brass plate being cool, lay the cell upon it again, and place the burner at its lowest possible point. The selenium will soon begin to crystallise, as evidenced by its surface assuming a dull leaden appearance. (If the crystallisation has not begur in five minutes, raise the burner an inch or two.) In from five to ten minutes the whole of the selenium should be crystallised. Then very gradually raise the burner until signs of fusion just begin to appear. This will probably take place when the flame is within 3 inches of the brass. Instantly remove the burner, and in about ten seconds re-crystallisation will occur. Now fix the burner $\frac{1}{2}$ inch below the point at which it was when fusion commenced, and let it remain for four hours, merely looking at it from time to time to ascertain that, owing to increase of gas pressure or other causes, the heat has not become too great. After four hours begin the cooling by lowering the burner an inch or two, and repeat this operation every ten or fifteen minutes, until the burner is at its lowest point. Then slightly lower the gas-flame at short intervals, until it is finally extinguished. When the brass plate is quite cool the cell may be removed.

I may mention that I first made a cell of this form, which I believe to be original, on October $28 .{ }^{1}$ If the two wires were wound on a cylinder made of some suitable non-conductor (e.s.s. slate) with a double screw cut upon its surface, a cell might be formed which, it appears to me, would unite all the advantages of $\mathrm{Mr}$. Bell's with far greater simplicity.

My experiments were made with the transmitter and selenium cell above described, a magic-lantern with a 4 -inch condenser, the focussing lenses being removed, two plano-convex lenses obtained by separating a $3 \frac{1}{2}$-inch condenser, a "blow-through" lime-light, a battery of eleven cells (small Leclanche's answer well), and a pair of Bell telephones. It is essential that the bobbins of the latter be wound with finer wire than that generally used. Mine contain No. 40 (instead of 35 or 36 ), and I intend to try 42. Their diameter is also larger than usual-r $\mathrm{r}_{4}^{3}$ inch.

The transmitter is clamped so that its axis is inclined at an angle of about $30^{\circ}$ to that of the lantern condenser, the centre of the mirror being 7 or 8 inches from the centre of the condenser; and the position of the limelight is so adjusted that the condensed rays may just cover the whole surface of the mirror.

The reflected beam is rendered as nearly parallel as possible by one of the plano-convex lenses (this can only be done approximately), while the other, placed a foot or two away, concentrates the light upon the selenium cell, forming an elliptical image of the mirror. The major axis of the ellipse should be parallel to the length of the cell, and the minor axis slightly longer than its width. A great deal depends upon the focussing, and the best results have been obtained when the image of the mirror was not quite sharp. The selenium cell is joined in circuit with the battery and the pair of telephones, the latter being for obvious reasons placed in a distant room. The arrangements are now complete, and a person listening with a telephone applied to each ear will, if everything is right, plainly hear words which are spoken into the transmitter. When I first made the experiment I was so much astonished at the distinctness of the reproduction that I believed that one of the battery connections must be

I If a larger surface is desired, two or more of these cells may be placed together side by side, the ends of the wires being properly connected. The width of inch for a single cell cannot be much exceeded, because the expansion produced by the heat necessary for melting the selenium would make the wires on a wider surface so loose as to touch each other. defective, thus acting like a microphone. This was disproved by screening the mirror, when all sound instantly ceased.

Though the articulation is not perfect, it is far better than I had expected, judging from the accounts of the performances of the photophone in Paris. A leading article might not be altogether intelligible, but ordinary colloquial phrases are readily iunderstood. The loudness of the reproduced speech varies in an unaccountable manner. Sometimes the voice is rendered almost as loudly as in an ordinary telephone; at other times, under apparently the same conditions, it is scarcely audible. Alternations from loudness to faintness, and vice vers $\hat{a}$, frequently occur in a single sentence.

The distances across which the beam is carried have varied in my experiments from I foot (when the two plano-convex lenses were in actual contact) to rather more than 4 feet. ${ }^{1}$ With a larger receiving lens this distance could be greatly extended, especially if the electric light were used.

For the "musical " effects produced by an interrupted beam I use a disk of zinc I foot in diameter, having eight radial slits cut in it, and mounted upon a vacuum tube rotator, The cell is placed 6 inches from the lantern condenser, and the disk made to rotate close before it. The sound produced is very loud, and can be heard when the telephones are at a distance of a foot or more from the ears.

It is very singular, that whereas I have been so successful in repeating Mr. Bell's more complex experiments, I have utterly failed in all attempts to produce sound by the simple incidence of an interrupted beam upon a thin diaphragm. I have experimented with disks of ebonite varying from ${ }_{04}^{1}$ to $\frac{1}{4}$ inch in thickness, and with several metals, and can only suppose that my source of light is not sufficiently powerful. SHELFORD BIDWEI,L

\section{THE CHRONOGRAPH}

MESSRS. E. DENT AND CO., of the Strand and I Royal Exchange, London, have been for some time past at work upon three galvanic chronographs of unusual accuracy and power. They surpass in both respects, so far as we know, any similar instruments yet constructed and we believe, therefore, some account of them will be interesting to our readers. They are destined respectively for the Royal Observatory of Brussels, for the Japanese Government, and for the Egyptian Government.

The advantages of the "chronographic" registration of the times of observations in observatories are not to be gainsaid. In the absence of any such arrangement an astronomer, whilst watching through his telescope, has to compute the time by counting up the clock-beats. More often than not he will find that no clock-beat exactly coincides with the instant of his observation. He must then reckon the difference-the fraction of the second elapsed--by judgment as best he is able. Skilled observers can reckon to tenths of seconds, but these are large and coarse amounts compared with what may be noted upon such chronographs as those we are referring to. In any case the astronomer must make a hurried memorandum of his results; otherwise he is liable to forget them.

The Astronomer-Royal was, we believe, the first to introduce a system of astronomical chronograpbic measurement into England; and he designed and had constructed at the Royal Observatory a large apparatus for the purpose. The reader must bear in mind tbat though differing in some respects both in their mechanism and the means employed, the chronographs we are going to describe are fundamentally the same as the AstronomerRoyal's.

of With a $5 \frac{1}{2}$-inch receiving lens the distance has been increased to upwards of ro feet. 